Article

\title{
Five-Golden-Flowers Tea: Green Extraction and Hepatoprotective Effect against Oxidative Damage
}

\author{
Cai-Ning Zhao ${ }^{1,+}{ }^{\dagger}$, Guo-Yi Tang ${ }^{1,+}{ }^{+}$, Qing Liu ${ }^{1}$, Xiao-Yu Xu ${ }^{1}$, Shi-Yu Cao ${ }^{1}$, Ren-You Gan ${ }^{2}$, \\ Ke-Yi Zhang ${ }^{1}$, Shuang-Li Meng ${ }^{1}$ and Hua-Bin $\mathrm{Li}^{1,3, * \text { id }}$ \\ 1 Guangdong Provincial Key Laboratory of Food, Nutrition and Health, Guangdong Engineering Technology \\ Research Center of Nutrition Translation, Department of Nutrition, School of Public Health, \\ Sun Yat-Sen University, Guangzhou 510080, China; zhaocn@mail2.sysu.edu.cn (C.-N.Z.); \\ tanggy5@mail2.sysu.edu.cn (G.-Y.T.); liuq248@mail2.sysu.edu.cn (Q.L.); xuxy53@mail2.sysu.edu.cn (X.-Y.X.); \\ caoshy3@mail2.sysu.edu.cn (S.-Y.C.); zhangky6@mail2.sysu.edu.cn (K.-Y.Z.); \\ mengsh19@mail2.sysu.edu.cn (S.-L.M.) \\ 2 Department of Food Science \& Technology, School of Agriculture and Biology, Shanghai Jiao Tong \\ University, Shanghai 200240, China; renyougan@sjtu.edu.cn \\ 3 South China Sea Bioresource Exploitation and Utilization Collaborative Innovation Center, \\ Sun Yat-Sen University, Guangzhou 510006, China \\ * Correspondence: lihuabin@mail.sysu.edu.cn; Tel.: +86-20-873-323-91 \\ + These authors contributed equally to this work.
}

Received: 31 July 2018; Accepted: 28 August 2018; Published: 31 August 2018

\begin{abstract}
The consumption of herbal teas has become popular in recent years due to their attractive flavors and outstanding antioxidant properties. The Five-Golden-Flowers tea is a herbal tea consisting of five famous edible flowers. The effects of microwave-assisted extraction parameters on the antioxidant activity of Five-Golden-Flowers tea were studied by single-factor experiments, and further investigated using response surface methodology. Under the optimal parameters $(53.04 \mathrm{~mL} / \mathrm{g}$ of solvent/material ratio, $65.52{ }^{\circ} \mathrm{C}, 30.89 \mathrm{~min}$, and $500 \mathrm{~W}$ ), the ferric-reducing antioxidant power, Trolox equivalent antioxidant capacity, and total phenolic content of the herbal tea were $862.90 \pm 2.44 \mu \mathrm{mol}$ $\mathrm{Fe}^{2+} / \mathrm{g}$ dry weight (DW), $474.37 \pm 1.92 \mu \mathrm{mol}$ Trolox/g DW, and $65.50 \pm 1.26 \mathrm{mg}$ gallic acid equivalent (GAE)/g DW, respectively. The in vivo antioxidant activity of the herbal tea was evaluated on alcohol-induced acute liver injury in mice. The herbal tea significantly decreased the levels of aspartate aminotransferase, total bilirubin, and malonaldehyde at different doses $(200,400$, and $800 \mathrm{mg} / \mathrm{kg})$; improved the levels of liver index, serum triacylglycerol, and catalase at dose of $800 \mathrm{mg} / \mathrm{kg}$. These results indicated its role in alleviating hepatic oxidative injury. Besides, rutin, chlorogenic acid, epicatechin, gallic acid, and $p$-coumaric acid were identified and quantified by high performance liquid chromatography (HPLC), which could contribute to the antioxidant activity of the herbal tea.
\end{abstract}

Keywords: herbal tea; antioxidant activity; polyphenol; microwave-assisted extraction; response surface methodology; liver injury

\section{Introduction}

The oxidative damage induced by excessive free radicals is responsible for the pathogenesis of chronic diseases, which has attracted considerable public concern [1]. Natural products could be utilized in the prevention and treatment of chronic diseases, such as cancer and cardiovascular disease, partly due to their potent antioxidant activities [2,3].

Several herbal teas were found to possess abundant natural antioxidants which can strengthen the antioxidant defense system and have the potential to prevent diseases induced by oxidative stress [4,5]. Rose (Rosa rugosa), osmanthus (Osmanthus fragrans), chrysanthemum (Flos chrysanthemi), 
honeysuckle (Lonicera japonica), and jasmine (Jasminum sambac) are five important flowers with various health benefits and have been consumed as herbal teas for a long time [6]. The Five-Golden-Flowers tea is a herbal tea, and consists of these five flowers, with satisfied sensory properties and plentiful antioxidants.

In this study, the effects of microwave-assisted extraction parameters on the antioxidant activity of Five-Golden-Flowers tea were studied. Furthermore, the alcohol-induced acute liver injury in Kunming mice model was utilized to evaluate the in vivo antioxidant and hepatoprotective activities of the herbal tea. Additionally, the phenolic compounds presented in the herbal tea were identified and quantified by high performance liquid chromatography (HPLC). This study will facilitate the exploration of the herbal tea as a good source of natural antioxidants for preventing several diseases induced by oxidative stress.

\section{Results and Discussion}

\subsection{Results of Single-Factor Tests}

Several mechanisms are involved in the antioxidant activities of antioxidants, such as free radical scavenging, metal ions chelating, and stimulating endogenous antioxidant compounds [7]. Thus, it is necessary to detect the in vitro antioxidant capacities through several methods with various testing principles [8]. The ferric-reducing antioxidant power (FRAP) and Trolox equivalent antioxidant capacity (TEAC) are two common assays to rapidly evaluate the antioxidant capacities [9]. The FRAP assay detects the ferric ions reducing ability of the herbal tea, while the TEAC assay detects the free radical scavenging activity.

Extraction procedure can influence the yield, composition, and biological activity of the extract $[10,11]$. The influence of extraction parameters on antioxidant capacities measured by FRAP and TEAC, as well as total phenolic content (TPC) was explored in single-factor tests (Figure 1).

The impacts of ratio of solvent to material ( $\mathrm{S} / \mathrm{M}$ ratio) on antioxidant values were studied when other parameters were fixed as $30{ }^{\circ} \mathrm{C}, 30 \mathrm{~min}$, and $500 \mathrm{~W}$ (Figure 1a). The antioxidant values increased significantly from 10 to $40 \mathrm{~mL} / \mathrm{g}$ of S/M ratio. From 40 to $50 \mathrm{~mL} / \mathrm{g}$ of S/M ratio, the FRAP value increased non-significantly, while the values of TEAC and TPC increased significantly. Significant decreases of the antioxidant values were observed from 50 to $60 \mathrm{~mL} / \mathrm{g}$ of S/M ratio. At the optimal $50 \mathrm{~mL} / \mathrm{g}$ of $\mathrm{S} / \mathrm{M}$ ratio, the mass transfer probably reached the maximum.

As shown in Figure 1b, the antioxidant values varied greatly depending on temperature under conditions of $50 \mathrm{~mL} / \mathrm{g}$ of S/M ratio, $30 \mathrm{~min}$, and $500 \mathrm{~W}$. The antioxidant values markedly improved as the temperature increased from 20 to $60{ }^{\circ} \mathrm{C}$, and kept almost constant when the temperature continued to rise. To save energy, $60{ }^{\circ} \mathrm{C}$ was selected in subsequent tests.

Under a certain procedure $\left(50 \mathrm{~mL} / \mathrm{g}\right.$ of $\mathrm{S} / \mathrm{M}$ ratio, $60^{\circ} \mathrm{C}$, and $\left.500 \mathrm{~W}\right)$, the antioxidant values improved from 10 to 30 min extraction, and showed a downward trend with further increasing time (Figure 1c), which might cause the degradation of antioxidants [12]. Hence, 30 min is optimal for the extraction procedure.

The sample was extracted under $50 \mathrm{~mL} / \mathrm{g}$ of $\mathrm{S} / \mathrm{M}$ ratio, $60{ }^{\circ} \mathrm{C}$, and $30 \mathrm{~min}$, with different levels of microwave power (Figure 1d). Although the antioxidant values reached the peak at $600 \mathrm{~W}$, there was no significant difference between 500 and $600 \mathrm{~W}$. In consideration of energy-saving, $500 \mathrm{~W}$ was more suitable in the extraction of antioxidants. 


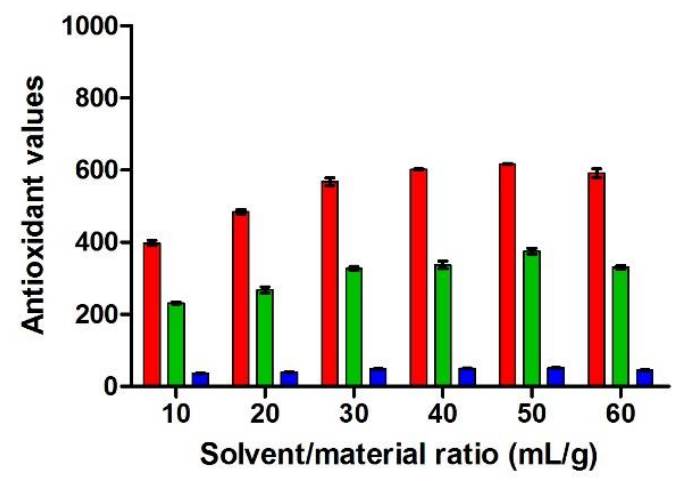

(a)

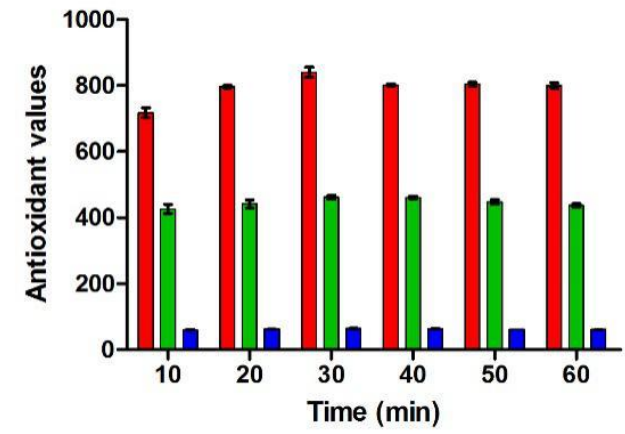

(c)
FRAP $\left(\mu \mathrm{mol} \mathrm{Fe} \mathrm{Fe}^{2+} / \mathrm{g} \mathrm{DW}\right)$

TEAC ( $\mu \mathrm{mol}$ Trolox/g DW)

TPC (mg GAE/g DW)

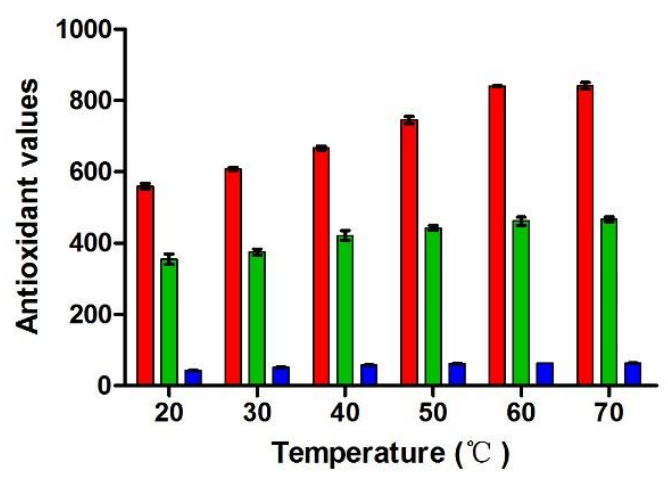

(b)

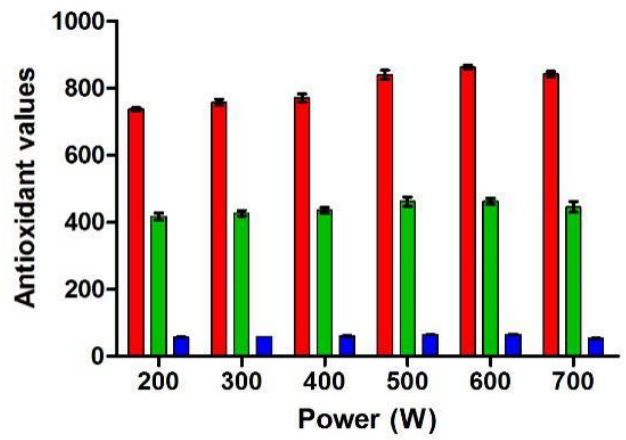

(d)

Figure 1. Effects of solvent/material ratio (a), temperature (b), time (c), and microwave power (d) on antioxidant values. GAE: gallic acid equivalent; DW: dry weight.

\subsection{Results of Response Surface Methodology Tests}

\subsubsection{Results of Central Composite Design}

Taking into consideration the results of single-factor tests, three dominant variables, i.e., S/M ratio, temperature, and time were further optimized by response surface methodology (RSM) using central composite design (CCD). The ranges of these 3 process variables were designed as $\mathrm{S} / \mathrm{M}$ ratio $\left(X_{1} ; 40,50\right.$, and $\left.60 \mathrm{~mL} / \mathrm{g}\right)$, temperature $\left(X_{2} ; 50,60\right.$, and $\left.70{ }^{\circ} \mathrm{C}\right)$, and time $\left(X_{3} ; 20,30\right.$, and $\left.40 \mathrm{~min}\right)$. The actual and coded levels of the 3 independent variables, and their corresponding response values (actual and predicted) are listed in Table 1. 
Table 1. Central composite design, actual and coded levels of independent variables, and corresponding actual and predicted values of responses.

\begin{tabular}{|c|c|c|c|c|c|c|c|c|c|}
\hline \multirow{2}{*}{ Run } & \multirow{2}{*}{ S/M Ratio $\left(X_{1}, \mathrm{~mL} / \mathrm{g}\right)$} & \multirow{2}{*}{ Temperature $\left(\mathrm{X}_{2},{ }^{\circ} \mathrm{C}\right)$} & \multirow{2}{*}{ Time $\left(X_{3}, \min \right)$} & \multicolumn{2}{|c|}{$\operatorname{FRAP}\left(\mathrm{Y}_{1}, \mu \mathrm{mol} \mathrm{Fe}{ }^{2+} / \mathrm{g}\right.$ DW $)$} & \multicolumn{2}{|c|}{ TEAC $\left(Y_{2}, \mu \mathrm{mol}\right.$ Trolox/g DW $)$} & \multicolumn{2}{|c|}{ TPC $\left(Y_{3}\right.$, mg GAE/g DW $)$} \\
\hline & & & & Actual & Predicted & Actual & Predicted & Actual & Predicted \\
\hline 1 & $33.18(-1.68)$ & $60(0)$ & $30(0)$ & 730.34 & 739.28 & 400.82 & 408.20 & 55.49 & 55.93 \\
\hline 2 & $40(-1)$ & $50(-1)$ & $40(1)$ & 717.07 & 695.95 & 356.78 & 351.29 & 50.95 & 50.97 \\
\hline 4 & $60(1)$ & $70(1)$ & $20(-1)$ & 769.67 & 787.98 & 426.78 & 430.07 & 59.66 & 59.55 \\
\hline 5 & $50(0)$ & $60(0)$ & $13.18(-1.68)$ & 726.33 & 723.71 & 395.54 & 398.51 & 56.75 & 56.96 \\
\hline 6 & $50(0)$ & $60(0)$ & $30(0)$ & 837.24 & 840.61 & 459.39 & 461.70 & 63.69 & 64.40 \\
\hline 7 & $50(0)$ & $60(0)$ & $30(0)$ & 843.60 & 840.61 & 445.18 & 461.70 & 64.19 & 64.40 \\
\hline 8 & $50(0)$ & $60(0)$ & $30(0)$ & 860.73 & 840.61 & 466.76 & 461.70 & 65.04 & 64.40 \\
\hline 10 & $50(0)$ & $60(0)$ & $46.82(1.68)$ & 739.25 & 745.84 & 396.43 & 396.57 & 57.51 & 57.43 \\
\hline 11 & $60(1)$ & $50(-1)$ & $40(1)$ & 716.60 & 720.97 & 376.63 & 386.82 & 56.28 & 56.62 \\
\hline 12 & $50(0)$ & $43.18(-1.68)$ & $30(0)$ & 677.58 & 691.54 & 347.78 & 342.54 & 50.84 & 50.52 \\
\hline 13 & $50(0)$ & $60(0)$ & $30(0)$ & 814.25 & 840.61 & 476.77 & 461.70 & 64.97 & 64.40 \\
\hline 14 & $66.82(1.68)$ & $60(0)$ & $30(0)$ & 800.50 & 795.53 & 442.40 & 438.13 & 60.81 & 60.50 \\
\hline 15 & $60(1)$ & $70(1)$ & $40(1)$ & 839.67 & 834.47 & 446.86 & 440.56 & 60.28 & 60.29 \\
\hline 16 & $40(-1)$ & $70(1)$ & $20(-1)$ & 753.28 & 746.10 & 442.40 & 430.01 & 60.19 & 59.77 \\
\hline 17 & $40(-1)$ & $50(-1)$ & $20(-1)$ & 713.73 & 716.12 & 359.99 & 364.09 & 51.25 & 51.15 \\
\hline 18 & $50(0)$ & $60(0)$ & $30(0)$ & 853.40 & 840.61 & 466.76 & 461.70 & 63.87 & 64.40 \\
\hline 19 & $50(0)$ & $60(0)$ & $30(0)$ & 835.10 & 840.61 & 455.90 & 461.70 & 64.69 & 64.40 \\
\hline
\end{tabular}

FRAP: ferric-reducing antioxidant power; TEAC: Trolox equivalent antioxidant capacity; TPC: total phenolic content. 


\subsubsection{Model Fitting}

The actual values of FRAP, TEAC, and TPC under 20 experimental combinations varied depending on the variance of extraction procedure, and were fitted into Equations (1)-(3) to evaluate the relationship between variables $\left(\mathrm{X}_{1}-\mathrm{S} / \mathrm{M}\right.$ ratio, $\mathrm{X}_{2}$-temperature, $\mathrm{X}_{3}$-time) and each response with non-significant items being removed:

$$
\begin{gathered}
\mathrm{Y}_{\text {FRAP }}=840.61+16.72 \mathrm{X}_{1}+35.87 \mathrm{X}_{2}-25.88 \mathrm{X}_{1}{ }^{2}-31.38 \mathrm{X}_{2}{ }^{2}-37.42 \mathrm{X}_{3}{ }^{2} \\
\mathrm{Y}_{\text {TEAC }}=461.70+8.90 \mathrm{X}_{1}+29.91 \mathrm{X}_{2}-13.63 \mathrm{X}_{1}{ }^{2}-24.34 \mathrm{X}_{2}{ }^{2}-22.69 \mathrm{X}_{3}{ }^{2} \\
\mathrm{Y}_{\text {TPC }}=64.40+1.36 \mathrm{X}_{1}+3.07 \mathrm{X}_{2}-1.09 \mathrm{X}_{1} \mathrm{X}_{2}-2.19 \mathrm{X}_{1}{ }^{2}-3.08 \mathrm{X}_{2}{ }^{2}-2.55 \mathrm{X}_{3}{ }^{2}
\end{gathered}
$$

As shown in Table 2, the analysis of variance (ANOVA) of FRAP indicated that the model was significant $(\mathrm{F}=23.92, p<0.0001)$. The non-significance $(p=0.4336)$ of lack-of-fit testing further verified the suitability of the model. Besides, the determination coefficient value $\left(R^{2}\right)$ of 0.9556 suggested that $95.56 \%$ of the variation could be explained by the fitted model. Furthermore, the adjusted $R^{2}$ of 0.9156 was closed to $R^{2}$, which proved the high correlation between the actual responses and the predicted responses. In a similar way, the models of TEAC and TPC were also suitable to predict the real relationship between the independent variables and the response.

\subsubsection{Graphical Analysis}

The 3D response surfaces plots visually illustrated the relationships between independent variables and response values (Figure 2). The interactions of time and temperature on the FRAP, TEAC, and TPC values were plotted at a fixed extraction S/M ratio of $50 \mathrm{~mL} / \mathrm{g}$ (Figure 2a-c). The increase of temperature obviously elevated the response values, and reached the peak at $65{ }^{\circ} \mathrm{C}$, while the response values increased slightly with the increase of time from $20 \mathrm{~min}$ to $30 \mathrm{~min}$. Figure $2 \mathrm{~d}-\mathrm{f}$ shows the interactions between time and $\mathrm{S} / \mathrm{M}$ ratio on the response values at $60^{\circ} \mathrm{C}$. The effect of time on the response values was similar to that shown in Figure 2a-c. As the S/M ratio increased from 40 to $50 \mathrm{~mL} / \mathrm{g}$, the response values improved markedly, then decreased as the $\mathrm{S} / \mathrm{M}$ ratio continued to increase. Figure $2 \mathrm{~g}-\mathrm{i}$ plots the interactions of $\mathrm{S} / \mathrm{M}$ ratio and extraction temperature on the response values at $30 \mathrm{~min}$, which followed a similar trend with those results in Figure 2a-f. Considering the results of response surfaces plots and the ANOVA in Table 2, it could be concluded that S/M ratio and extraction temperature significantly affected the response values. 
Table 2. ANOVA of the models of FRAP, TEAC, and TPC.

\begin{tabular}{|c|c|c|c|c|c|c|c|c|c|c|c|c|c|c|c|}
\hline \multirow{2}{*}{ Source } & \multicolumn{5}{|c|}{ FRAP } & \multicolumn{5}{|c|}{ TEAC } & \multicolumn{5}{|c|}{ TPC } \\
\hline & $\begin{array}{l}\text { Sum of } \\
\text { Squares }\end{array}$ & df & $\begin{array}{l}\text { Mean } \\
\text { Square }\end{array}$ & F value & $p$ Value & $\begin{array}{l}\text { Sum of } \\
\text { Squares }\end{array}$ & df & $\begin{array}{l}\text { Mean } \\
\text { Square }\end{array}$ & F Value & $p$ Value & $\begin{array}{l}\text { Sum of } \\
\text { Squares }\end{array}$ & df & $\begin{array}{l}\text { Mean } \\
\text { Square }\end{array}$ & F Value & $p$ Value \\
\hline Model & $61,370.96$ & 9 & 6819.00 & 23.92 & $<0.0001$ & $29,448.79$ & 9 & 3272.09 & 29.03 & $<0.0001$ & 417.00 & 9 & 46.33 & 169.39 & $<0.0001$ \\
\hline $\mathrm{X}_{1}$ & 3818.96 & 1 & 3818.96 & 13.39 & 0.0044 & 1080.92 & 1 & 1080.92 & 9.59 & 0.0113 & 25.22 & 1 & 25.22 & 92.19 & $<0.0001$ \\
\hline$x_{2}$ & $17,571.62$ & 1 & 17571.62 & 61.63 & $<0.0001$ & $12,221.12$ & 1 & $12,221.12$ & 108.43 & $<0.0001$ & 128.95 & 1 & 128.95 & 471.43 & $<0.0001$ \\
\hline$x_{3}$ & 591.38 & 1 & 591.38 & 2.07 & 0.1804 & 4.54 & 1 & 4.54 & 0.04 & 0.8450 & 0.27 & 1 & 0.27 & 0.97 & 0.3468 \\
\hline $\mathrm{x}_{1} \mathrm{X}_{2}$ & 1289.81 & 1 & 1289.81 & 4.52 & 0.0593 & 165.53 & 1 & 165.53 & 1.47 & 0.2534 & 9.48 & 1 & 9.48 & 34.67 & 0.0002 \\
\hline$x_{1} x_{3}$ & 575.62 & 1 & 575.62 & 2.02 & 0.1858 & 149.21 & 1 & 149.21 & 1.32 & 0.2767 & 1.13 & 1 & 1.13 & 4.14 & 0.0692 \\
\hline $\mathrm{X}_{2} \mathrm{X}_{3}$ & 535.63 & 1 & 535.63 & 1.88 & 0.2005 & 18.09 & 1 & 18.09 & 0.16 & 0.6971 & 0.17 & 1 & 0.17 & 0.63 & 0.4473 \\
\hline$x_{1}^{2}$ & 9652.51 & 1 & 9652.51 & 33.85 & 0.0002 & 2675.42 & 1 & 2675.42 & 23.74 & 0.0006 & 69.13 & 1 & 69.13 & 252.72 & $<0.0001$ \\
\hline$X_{2}^{2}$ & $14,187.47$ & 1 & $14,187.47$ & 49.76 & $<0.0001$ & 8540.02 & 1 & 8540.02 & 75.77 & $<0.0001$ & 136.96 & 1 & 136.96 & 500.73 & $<0.0001$ \\
\hline$x_{3}^{2}$ & $20,175.95$ & 1 & $20,175.95$ & 70.76 & $<0.0001$ & 7416.22 & 1 & 7416.22 & 65.80 & $<0.0001$ & 93.77 & 1 & 93.77 & 342.80 & $<0.0001$ \\
\hline Residual & 2851.23 & 10 & 285.12 & & & 1127.15 & 10 & 112.71 & & & 2.74 & 10 & 0.27 & & \\
\hline Lack of fit & 1537.40 & 5 & 307.48 & 1.17 & 0.4336 & 537.00 & 5 & 107.40 & 0.91 & 0.5400 & 1.09 & 5 & 0.22 & 0.66 & 0.6699 \\
\hline Pure error & 1313.83 & 5 & 262.77 & & & 590.15 & 5 & 118.03 & & & 1.65 & 5 & 0.33 & & \\
\hline Cor total & $64,222.19$ & 19 & & & & $30,575.93$ & 19 & & & & 419.73 & 19 & & & \\
\hline$R^{2}$ & 0.9556 & & & & & 0.9631 & & & & & 0.9935 & & & & \\
\hline $\begin{array}{c}\text { Adjusted } \\
\qquad R^{2}\end{array}$ & 0.9156 & & & & & 0.9300 & & & & & 0.9876 & & & & \\
\hline
\end{tabular}




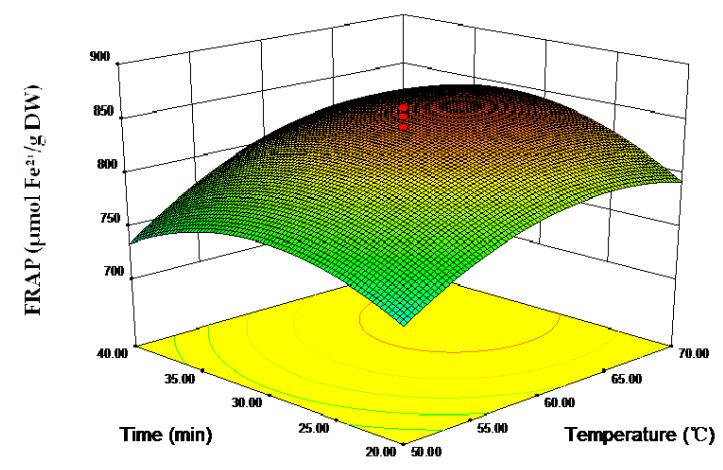

(a)

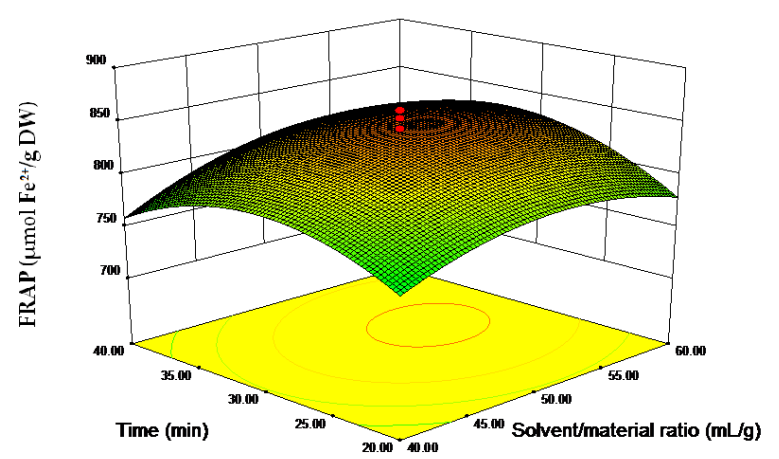

(d)

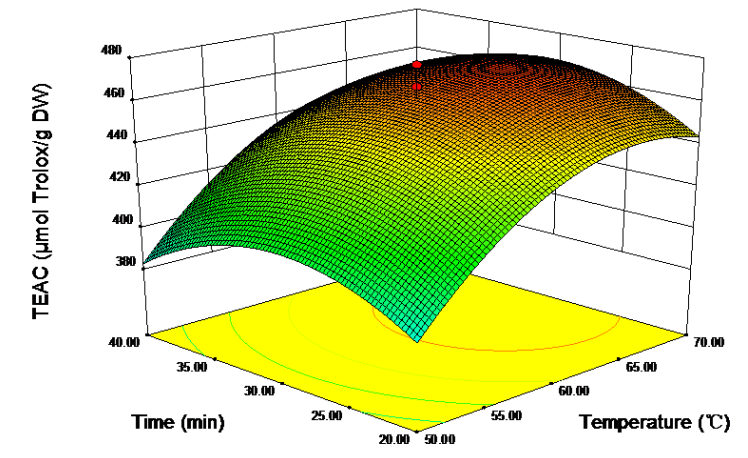

(b)

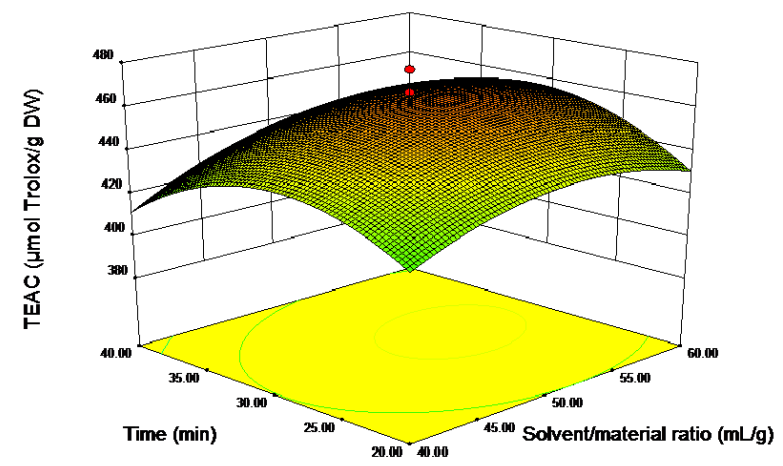

(e)

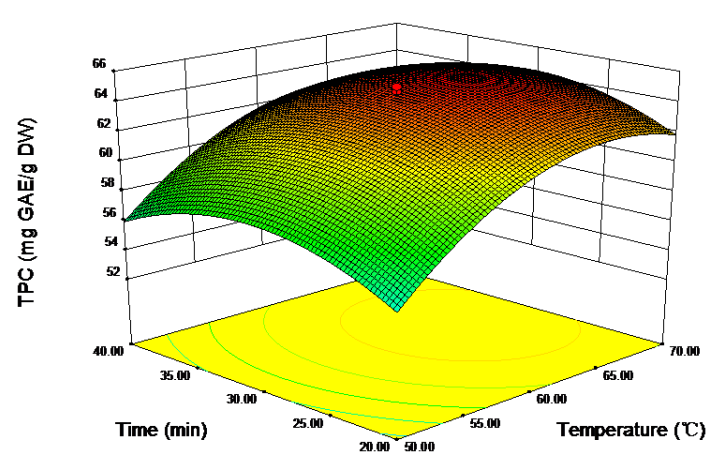

(c)

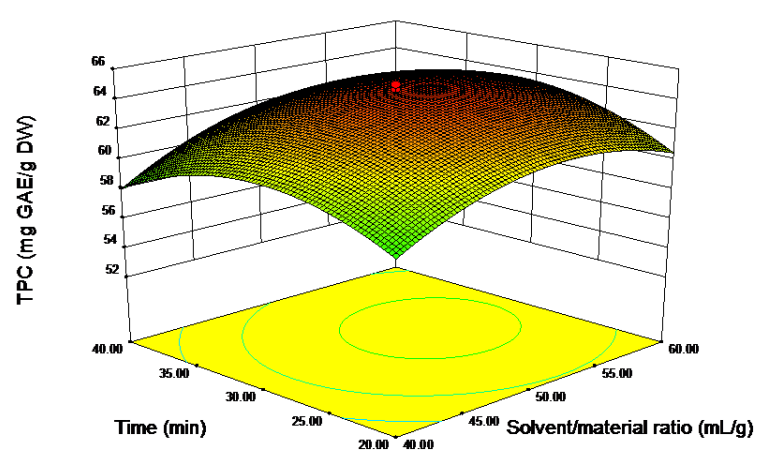

(f)

Figure 2. Cont. 


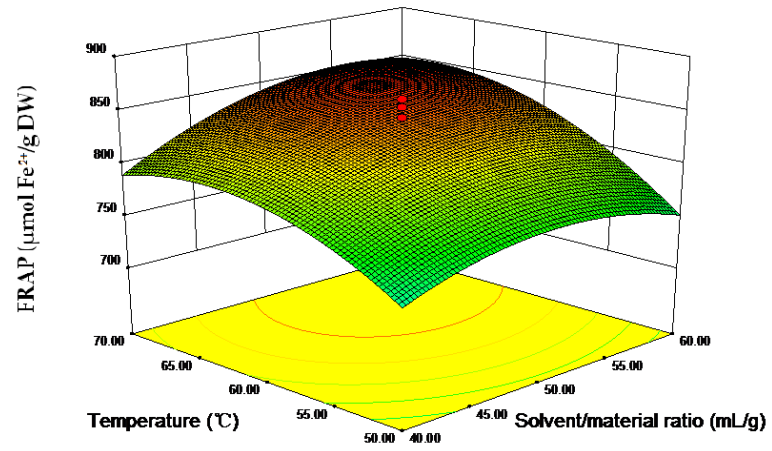

(g)

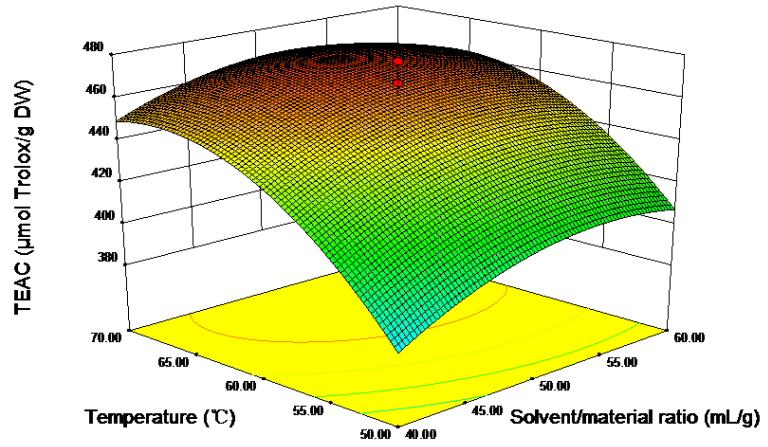

(h)

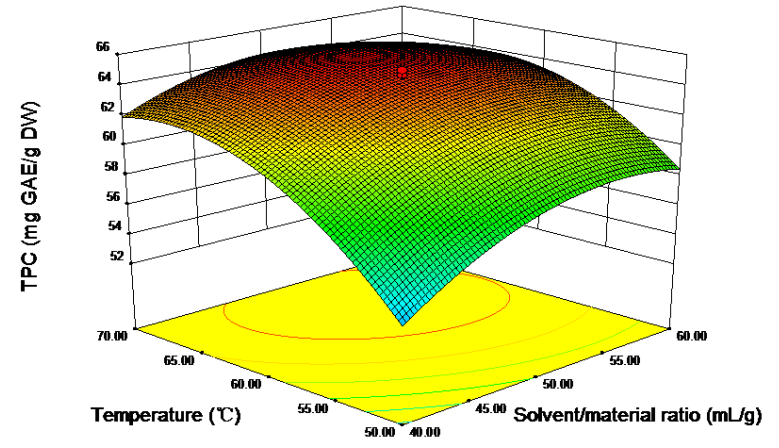

(i)

Figure 2. Graphical analysis of effects of temperature and time on FRAP (a), TEAC (b), and TPC (c); solvent/material ratio and time on FRAP (d), TEAC (e), and TPC (f); solvent/material ratio and temperature on FRAP (g), TEAC (h), and TPC (i). 


\subsubsection{Optimal Extraction Parameters and Responses}

Under optimal parameters $\left(53.04 \mathrm{~mL} / \mathrm{g}\right.$ of $\mathrm{S} / \mathrm{M}$ ratio, $65.52{ }^{\circ} \mathrm{C}, 30.89 \mathrm{~min}$, and $\left.500 \mathrm{~W}\right)$, the FRAP, TEAC, and TPC values were $862.90 \pm 2.44 \mu \mathrm{mol} \mathrm{Fe} \mathrm{Fe}^{2+} / \mathrm{g}$ dry weight (DW) of the herbal tea, $474.37 \pm 1.92 \mu \mathrm{mol}$ Trolox $/ \mathrm{g} \mathrm{DW}$, and $65.50 \pm 1.26 \mathrm{mg}$ gallic acid equivalent (GAE)/g DW, respectively, which were in accordance with the predicted ones (FRAP $=856.59 \mu \mathrm{mol} \mathrm{Fe}{ }^{2+} / \mathrm{g} \mathrm{DW}$ $\mathrm{TEAC}=471.44 \mu \mathrm{mol}$ Trolox $/ \mathrm{g} \mathrm{DW}, \mathrm{TPC}=65.18 \mathrm{mg}$ GAE$/ \mathrm{g} \mathrm{DW})$.

\subsection{Comparison of Different Extraction Methods}

The extraction efficiency of microwave-assisted extraction (MAE) was compared with traditional decocting and Soxhlet extraction in terms of time, temperature, solvent, and extraction yields (Table 3). MAE allowed a greater yield of natural antioxidants in herbal tea in comparison with decocting method. The FRAP, TEAC, and TPC values of MAE extract were 1.19, 1.27, and 1.18 times higher than those of decocting method. The high efficiency of MAE could be attributed to ionic conduction and dipole rotation provided by microwave energy, which could rapidly increase the inner temperature of the plant cells [13-15]. Then, the sudden heat facilitated the fracture of cell walls and ultimately accelerated the release of antioxidants from the plant matrix into the solution [16-18].

Furthermore, MAE obtained similar antioxidant yields in comparison with Soxhlet extraction in relatively shorter time and lower temperature, which might protect some thermal unstable components from decomposition $[19,20]$. It should be pointed out that prolonged microwave irradiation time could also induce the degradation of some antioxidants as shown in Figure 1c. Thus, the optimization of the MAE parameters was essential for warranting the maximal extraction of natural antioxidants from herbal tea. Additionally, compared with Soxhlet extraction, MAE was conducted without organic solvent, which was green and economic.

Table 3. Comparison of three extraction methods.

\begin{tabular}{ccccccc}
\hline $\begin{array}{c}\text { Extraction } \\
\text { Methods }\end{array}$ & Solvent & $\begin{array}{c}\text { Temperature } \\
\left({ }^{\circ} \mathbf{C}\right)\end{array}$ & Time & $\begin{array}{c}\text { FRAP }(\mu \mathrm{mol} \\
\left.\mathbf{F e}^{2+} / \mathbf{g} \text { DW }\right)\end{array}$ & $\begin{array}{c}\text { TEAC }(\mu \mathrm{mol} \\
\text { Trolox/g DW })\end{array}$ & $\begin{array}{c}\text { TPC }(\mathbf{m g} \\
\mathbf{G A E} / \mathbf{g} \text { DW })\end{array}$ \\
\hline $\begin{array}{c}\text { Decocting method } \\
\text { Soxhlet extraction }\end{array}$ & Distilled water & 65.52 & $30.89 \mathrm{~min}$ & $726.16 \pm 1.25$ & $372.61 \pm 1.33$ & $55.65 \pm 0.39$ \\
MAE & $50 \%$ ethanol & 95 & $4 \mathrm{~h}$ & $847.17 \pm 2.36$ & $479.15 \pm 1.26$ & $68.55 \pm 0.32$ \\
& Distilled water & 65.52 & $30.89 \mathrm{~min}$ & $862.90 \pm 2.44$ & $474.37 \pm 1.92$ & $65.50 \pm 1.26$ \\
\hline
\end{tabular}

\subsection{Correlations between FRAP, TEAC, and TPC}

The correlations of the actual values of FRAP, TEAC, and TPC presented in Table 1 were analyzed (Figure 3). The strong linear correlation between FRAP and TEAC $\left(R^{2}=0.833\right)$ implied that antioxidants in the herbal tea possessed both reducing $\mathrm{Fe}^{3+}$ to $\mathrm{Fe}^{2+}$ and scavenging 2,2'-azinobis(3-ethylbenothiazoline-6-sulphonic acid) (ABTS) free radicals activities. Besides, the strong linear correlation between TPC and FRAP/TEAC (FRAP vs. TPC, $R^{2}=0.825$; TEAC vs. TPC, $R^{2}=0.941$ ) indicated that phenolic compounds could be responsible for the reducing $\mathrm{Fe}^{3+}$ to $\mathrm{Fe}^{2+}$ and scavenging ABTS free radicals activities of the herbal tea. 


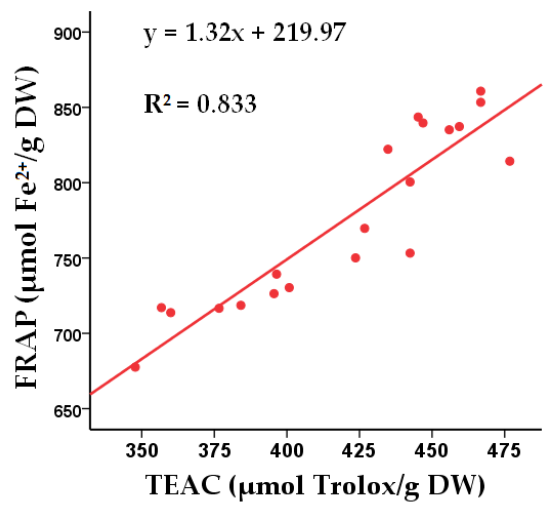

(a)

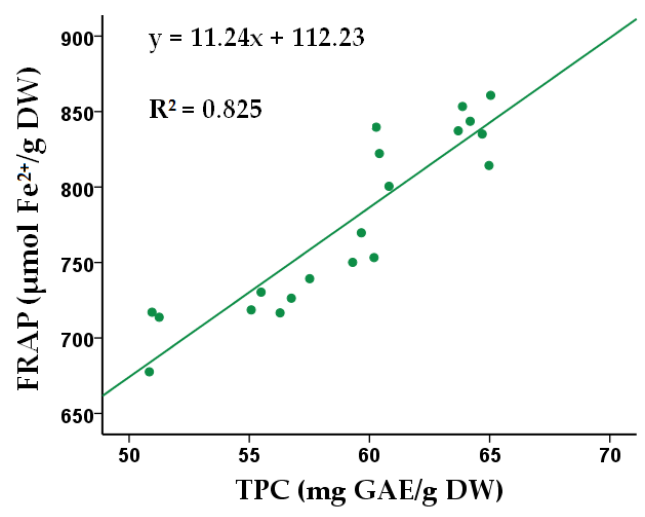

(b)

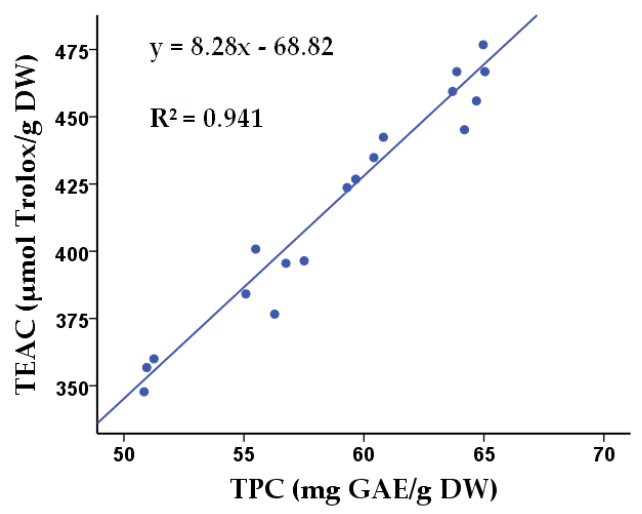

(c)

Figure 3. Correlations between values of FRAP and TEAC (a), FRAP and TPC (b), TEAC and TPC (c).

\subsection{Results of Animals Study}

\subsubsection{Hepatoprotective Effects of the Herbal Tea against Alcohol-Induced Injury}

The liver index (ratio of liver weight and body weight), and the levels of serum aspartate transaminase (AST), alanine transaminase (ALT), alkaline phosphatase (ALP), total bilirubin (TBIL), as well as the contents of serum and liver triglyceride (TG) were measured to assess effects of the herbal tea on liver injury (Table 4). AST and ALT are aminopherases concentrating in hepatocyte cytoplasm which will leak into plasma as hepatocytes are damaged by alcohol and its metabolites [21]. The impairment of hepatic conjugated bilirubin excretion causes the increase of serum TBIL, which reflects the functional lesion of the liver [22]. As shown in Table 4, the liver index $(p<0.01)$ and serum levels of AST $(p<0.01)$, ALT $(p<0.05)$, TBIL $(p<0.05)$, and serum TG $(p<0.05)$ were increased significantly in the model group compared with the control group, which indicated the liver injury induced by alcohol. The results showed that all three doses of herbal tea $(200,400$, and $800 \mathrm{mg} / \mathrm{kg})$ ameliorated the levels of AST and TBIL significantly. Moreover, high-dose treatment markedly decreased liver index compared with the model group $(p<0.05)$. Consumption of alcohol results in deposition of hepatic TG, which will be delivered into blood and cause the increase of serum TG. So the concentrations of TG in serum and liver need to be measured [23]. The value of serum TG was lower at dose of $800 \mathrm{mg} / \mathrm{kg}(p<0.05)$, indicating the role of the herbal tea in improving lipid metabolic abnormality induced by alcohol consumption [24]. Nevertheless, the difference in levels of ALP (target of hepatobiliary effect and cholestasis) and liver TG in 5 groups were non-significant. 
Table 4. Effects of the herbal tea on liver function.

\begin{tabular}{|c|c|c|c|c|c|c|c|}
\hline Group & Liver Index (\%) & AST (U/L) & ALT (U/L) & $\operatorname{ALP}(U / L)$ & TBIL $(\mu \mathrm{mol} / \mathrm{L})$ & Serum TG (mmol/L) & Liver TG (mmol/gprot) \\
\hline Control & $4.11 \pm 0.13$ & $115.25 \pm 9.99$ & $30.10 \pm 6.50$ & $318.67 \pm 39.39$ & $1.96 \pm 0.40$ & $0.88 \pm 0.23$ & $0.25 \pm 0.05$ \\
\hline Model & $4.58 \pm 0.32$ & $153.72 \pm 22.18 \#$ & $40.68 \pm 7.82$ \# & $303.33 \pm 49.79$ & $2.38 \pm 0.32^{\#}$ & $1.28 \pm 0.33^{\#}$ & $0.27 \pm 0.04$ \\
\hline $200 \mathrm{mg} / \mathrm{kg}$ & $4.43 \pm 0.15$ & $128.62 \pm 16.73 *$ & $32.77 \pm 5.63$ & $305.67 \pm 68.56$ & $1.70 \pm 0.39^{* *}$ & $0.99 \pm 0.38$ & $0.31 \pm 0.04$ \\
\hline $400 \mathrm{mg} / \mathrm{kg}$ & $4.51 \pm 0.21$ & $125.50 \pm 17.81$ * & $38.68 \pm 6.58$ & $327.83 \pm 69.15$ & $1.98 \pm 0.12 *$ & $1.01 \pm 0.32$ & $0.31 \pm 0.05$ \\
\hline $800 \mathrm{mg} / \mathrm{kg}$ & $4.25 \pm 0.22 *$ & $126.92 \pm 12.61 *$ & $35.38 \pm 6.10$ & $338.33 \pm 54.40$ & $1.83 \pm 0.23^{* *}$ & $0.91 \pm 0.05^{*}$ & $0.30 \pm 0.04$ \\
\hline
\end{tabular}

${ }^{\#} p<0.05,{ }^{\# \#} p<0.01$, the model group vs. the control group. ${ }^{*} p<0.05,{ }^{* *} p<0.01$, the treatment group vs. the model group. gprot: gram protein. 


\subsubsection{The In Vivo Antioxidant Activity of the Herbal Tea}

The antioxidant activity involves complicated mutual actions between the antioxidants and organisms [25], thus in vivo experiments need to be conducted. In this study, we employed an alcohol-induced acute liver injury model to analyze the in vivo antioxidant activities of the herbal tea. The decisive role of oxidative stress in alcohol-induced liver injury has been reported by substantial literature [26,27]. Excessive alcohol consumption is a major risk factor in the disorder of hepatic function, as it induces the generation of free radicals, consumes cellular antioxidants, and leads to hepatocellular oxidative stress [28].

The activity of antioxidant enzymes superoxide dismutase (SOD) and catalase (CAT), and the contents of glutathione (GSH) and malondialdehyde (MDA) in liver are important indices reflecting antioxidant activity in vivo $[29,30]$. It has been reported that alcohol induced the damage of antioxidant defense system presented as the reduction of the activity of main antioxidant enzymes such as SOD (remove superoxide) and CAT (remove $\mathrm{H}_{2} \mathrm{O}_{2}$ ) [29]. Besides, the content of MDA (product of lipid peroxidation induced by free radicals) is an indirect indicator of the degree of the liver peroxidation damage [30].

As shown in Table 5, the value of MDA was significantly increased $(p<0.01)$ and the levels of SOD and CAT were significantly decreased $(p<0.05) 6 \mathrm{~h}$ after consumption of alcohol when compared with the control group, indicating that alcohol impaired the antioxidant activity of liver. In comparison with the model group, all 3 doses of herbal tea $(200,400$, and $800 \mathrm{mg} / \mathrm{kg})$ significantly inhibited the increase of MDA value, and the high dose of the herbal tea significantly increased the CAT activity $(p<0.05)$. Furthermore, the content of GSH and the activity of SOD increased in comparison with the model group, though the differences were insignificant. These results indicated that the hepatoprotective actions of the herbal tea might be attributed to its antioxidant activity.

Table 5. Effects of herbal tea on MDA, GSH, SOD, and CAT.

\begin{tabular}{ccccc}
\hline Group & MDA (nmol/mgprot) & GSH ( $\mu$ mol/gprot) & SOD (U/mgprot) & CAT (U/mgprot) \\
\hline Control & $1.08 \pm 0.42$ & $8.39 \pm 0.91$ & $271.03 \pm 15.79$ & $62.46 \pm 2.74$ \\
Model & $1.96 \pm 0.70^{\# \#}$ & $5.88 \pm 1.01$ & $255.54 \pm 13.71^{\#}$ & $56.04 \pm 8.33^{\#}$ \\
$200 \mathrm{mg} / \mathrm{kg}$ & $1.00 \pm 0.25^{* *}$ & $5.99 \pm 1.09$ & $264.78 \pm 4.90$ & $51.19 \pm 2.25$ \\
$400 \mathrm{mg} / \mathrm{kg}$ & $0.87 \pm 0.12^{* *}$ & $8.63 \pm 0.64$ & $256.33 \pm 8.78$ & $57.49 \pm 4.58$ \\
$800 \mathrm{mg} / \mathrm{kg}$ & $0.82 \pm 0.17^{* *}$ & $10.05 \pm 0.69$ & $262.06 \pm 3.94$ & $62.57 \pm 4.18^{*}$ \\
\hline${ }^{\#} p<0.05,{ }^{\# \#} p<0.01$, the model group vs. the control group. ${ }^{*} p<0.05,{ }^{* *} p<0.01$, the treatment group vs. the \\
model group.
\end{tabular}

\subsubsection{Histopathological Evaluation}

Histopathological evaluation further revealed the protective role of the herbal tea against alcohol-induced liver injury (Figure 4). The control group showed no visible lesions (Figure 4a). In comparison with the control group, there were obvious pathologic changes (lipid droplets accumulation) in the model group. The liver sections of the model group were observed with $40 \times$ objective lens, and lipid droplets were found in less than $25 \%$ liver cells (Figure $4 \mathrm{~b}$ ). However, alcohol-induced lesion was attenuated in the 3 treatment groups (Figure 4c-e), displaying lighter steatosis as compared with the model group. 


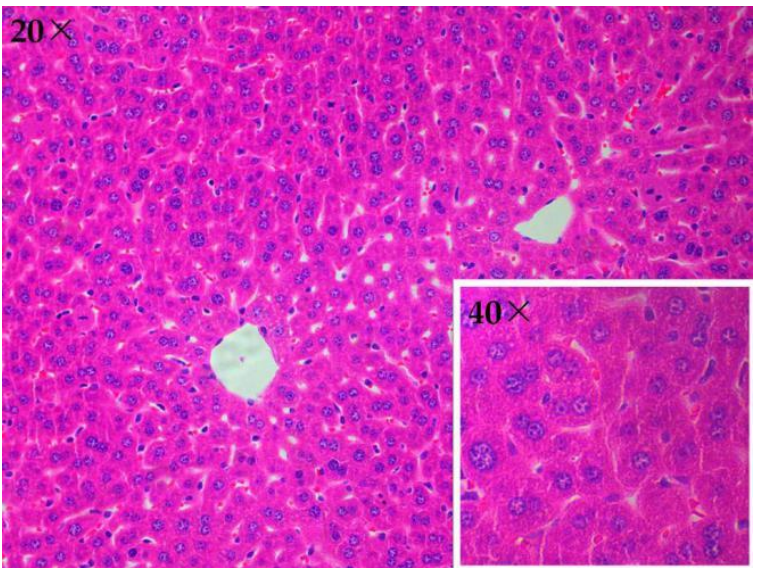

(a)

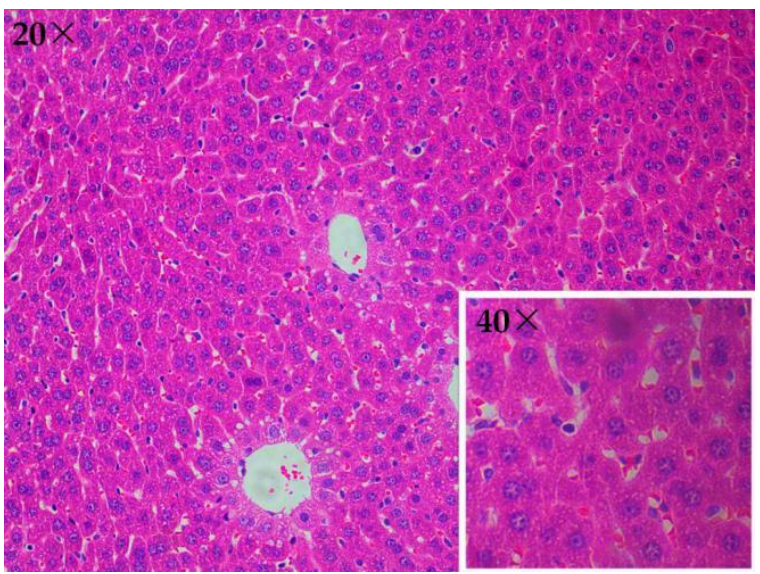

(c)

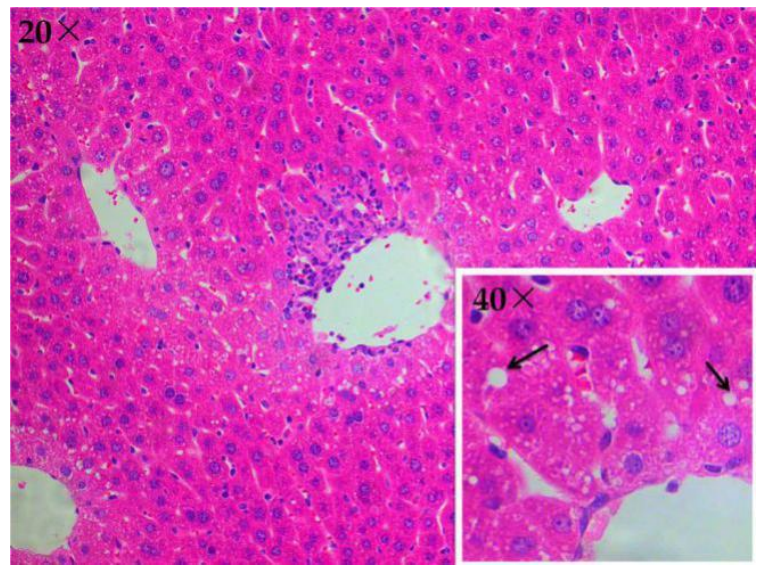

(b)

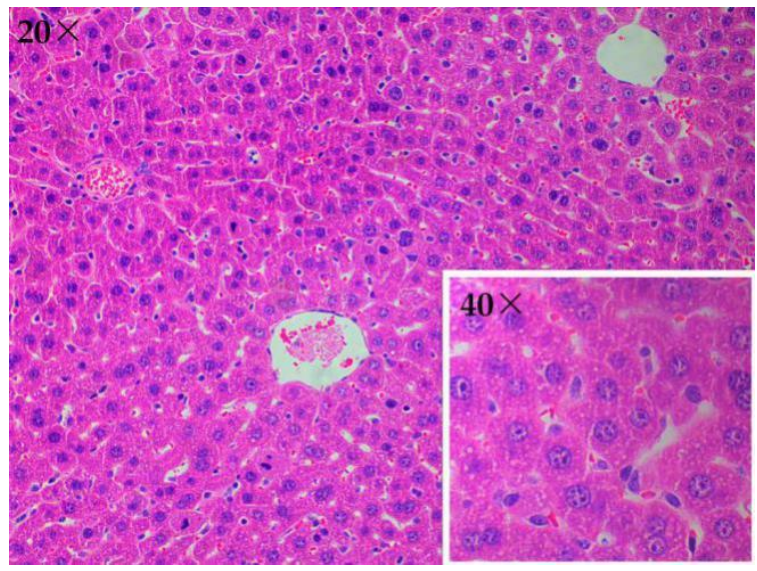

(d)

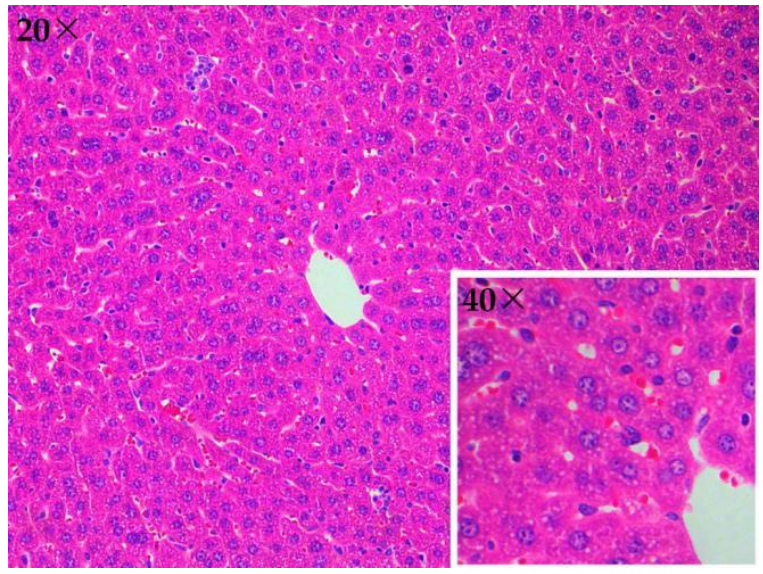

(e)

Figure 4. Hematoxylin-eosin stained liver sections of the control group (a), model group (b), $200 \mathrm{mg} / \mathrm{kg}$ group (c), $400 \mathrm{mg} / \mathrm{kg}$ group (d), and $800 \mathrm{mg} / \mathrm{kg}$ group (e). Arrow: lipid droplet.

\subsection{Analysis of Phenolic Compounds by HPLC}

Phenolic compounds in the extract of the herbal tea obtained using MAE under optimal parameters were identified and quantified by HPLC. Chromatograms under $276 \mathrm{~nm}$ of standard 
phenolic compounds and the herbal tea extract were presented in Figure 5. Five phenolic compounds, i.e., rutin, chlorogenic acid, epicatechin, gallic acid, and $p$-coumaric acid, were detected, with contents of $1.55 \pm 0.20 \mathrm{mg} / \mathrm{g}$ DW, $1.44 \pm 0.00 \mathrm{mg} / \mathrm{g} \mathrm{DW}, 0.71 \pm 0.06 \mathrm{mg} / \mathrm{g}$ DW, $0.67 \pm 0.02 \mathrm{mg} / \mathrm{g}$ DW, and $0.10 \pm 0.02 \mathrm{mg} / \mathrm{g}$ DW, respectively.

Rutin, the most abundant phenolic compound detected in the herbal tea, has potent in vitro antioxidant activity measured by various assays [31], and could increase the antioxidant status in mouse liver [32]. Moreover, a study demonstrated that chlorogenic acid treatment attenuated alcohol-induced liver injury through suppressing oxidative stress [33]. Besides, the other 3 phenolic compounds have also shown potent antioxidant activities [34]. Given these, the 5 phenolic compounds might be the bioactive components responsible for the antioxidant and hepatoprotective activity.

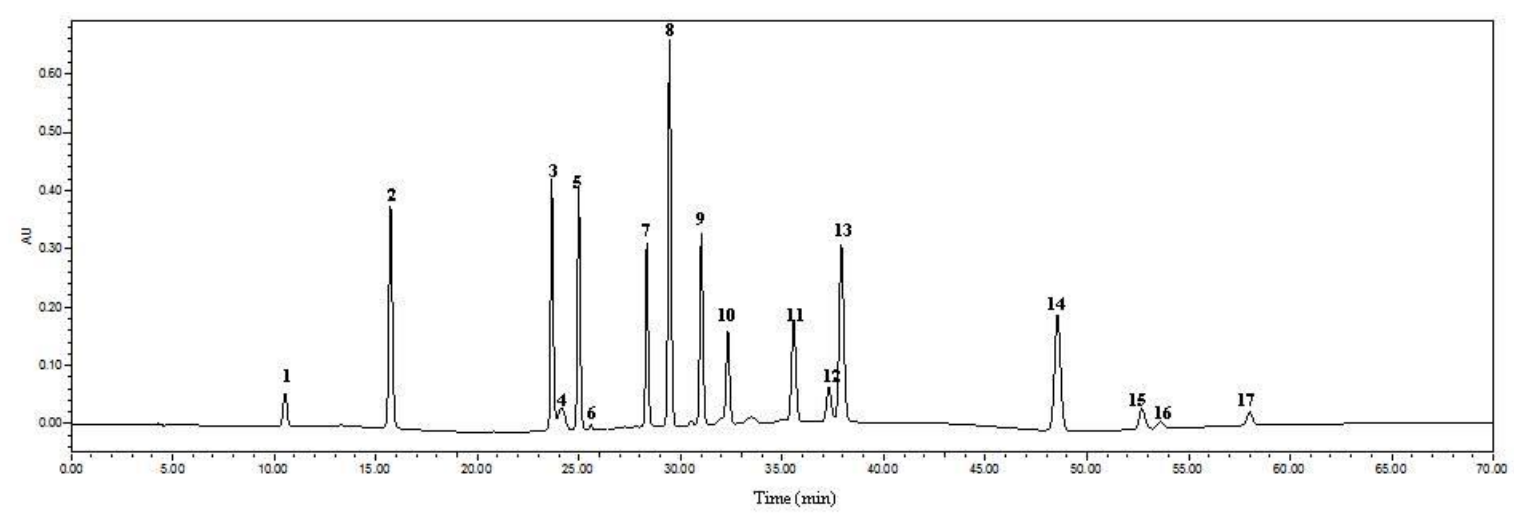

(a)

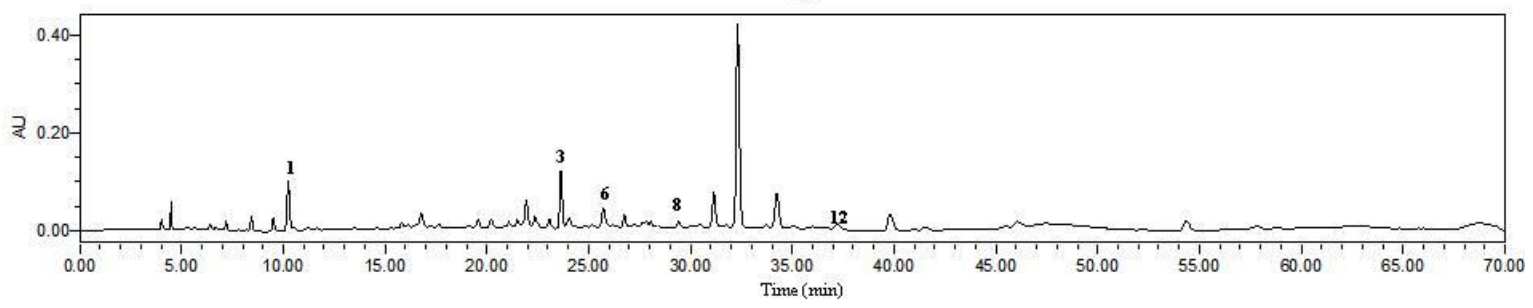

(b)

Figure 5. Chromatograms under $276 \mathrm{~nm}$ of standard phenolic compounds (a) and the herbal tea extract obtained using MAE under optimal parameters (b). 1. gallic acid; 2. protocatechuic acid; 3. chlorogenic acid; 4. cyanidin-3-glucoside; 5. caffeic acid; 6. epicatechin; 7. catechine; 8. p-coumaric acid; 9. ferulaic acid; 10. melatonin; 11. 2-hydroxycinnamic acid; 12 . rutin; 13 . resveratrol; 14 . daidzein; 15 . equol; 16. quercetin; 17 . genistein.

\section{Materials and Methods}

\subsection{Sample Preparation}

Dried flowers of rose, osmanthus, chrysanthemum, honeysuckle, and jasmine purchased from supermarket in Guangzhou, China were formulated in proportion of $28.57 \%, 28.57 \%, 21.43 \%, 14.29 \%$, and $7.14 \%$, respectively. The mixture was ground into particles using a grinder (RS-FS500B; Royalstar Co., Ltd., Hefei, Anhui, China), and then filtered through a 100 meshes sieve.

\subsection{Chemicals}

TPTZ (2,4,6-tri(2-pyridyl)-s-triazine), Folin \& Ciocalteu's phenol, Trolox (6-hydroxy-2,5,7,8tetramethylchromane-2-carboxylic acid), gallic acid, ABTS (2,2'-azino-bis(3-ethylbenothiazoline6-sulphonic acid) diammonium salt), and phenolic standards (such as rutin and epicatechin) were products of Sigma-Aldrich (Saint Louis, MO, USA). Chromatography-grade formic acid and methanol 
were purchased from Kermel Chemical Factory (Tianjin, China). All the other regents (such as sodium carbonate anhydrous) were of analytical grade, and were produced by Damao Reagent Factory (Tianjin, China). The total protein (TP), TG, MDA, GSH, SOD, and CAT kits were purchased from Nanjing Jiancheng Bioengineering Institute (Nanjing, China).

\subsection{Microwave-Assisted Extraction}

MAE was executed using a microwave extraction device (XH-100A; Xianghu Instrumental Company, Beijing, China). The sample $(0.200 \mathrm{~g})$ was extracted using a certain volume of distilled water in a tube. The tube was put into a water bath equipped with a temperature monitor. Then, the sample was extracted under pre-set process parameters, which was controlled by the software of the device. In the single-factor tests, the experimental parameters were set as: S/M ratio $(10,20,30$, 40, 50, and $60 \mathrm{~mL} / \mathrm{g})$, temperature $\left(20,30,40,50,60\right.$, and $\left.70{ }^{\circ} \mathrm{C}\right)$, time $(10,20,30,40,50$, and $60 \mathrm{~min})$, and microwave power $(200,300,400,500,600$, and $700 \mathrm{~W})$. Then, the S/M ratio, time, and temperature were further optimized using RSM, and their designed levels were displayed in Table 1, while the microwave power was fixed at $500 \mathrm{~W}$. After extraction, the mixture was centrifugated for $30 \mathrm{~min}$ at $4200 \mathrm{~g}$, and the supernatant was gathered.

\subsection{Decocting Extraction}

The $0.200 \mathrm{~g}$ powdered sample was immersed in $10.608 \mathrm{~mL}$ distilled water with stirring, and extracted for $30.89 \mathrm{~min}$ at $65.52{ }^{\circ} \mathrm{C}$ in a water bath shaker. After centrifugation ( $\left.4200 \mathrm{~g}, 30 \mathrm{~min}\right)$, the supernatant was collected.

\subsection{Soxhlet Extraction}

The Soxhlet extraction was executed according to the procedure previously reported [19]. The sample $(1.000 \mathrm{~g})$ was extracted by $200 \mathrm{~mL}$ of $50 \%(v / v)$ ethanol aqueous solution in a Soxhlet extractor at $95^{\circ} \mathrm{C}$ water bath for $4 \mathrm{~h}$. After extraction, the solution was collected.

\subsection{Measurement of Antioxidant Capacities and Total Phenolic Contents}

The FRAP, TEAC, and TPC of the herbal tea were measured based on procedures previously published [4], which were stated as $\mu \mathrm{mol} \mathrm{Fe}^{2+} / \mathrm{g}$ DW, $\mu$ mol Trolox/g DW, and mg GAE/g DW, respectively.

\subsection{Optimization of Extraction Parameters}

The influences of 4 process variables on antioxidant values (FRAP, TEAC, and TPC) were evaluated in single-factor tests. Then, 3 selected dominant factors were further optimized in following response surface methodology (RSM) by Design Expert 8.0.6 (Stat-Ease Inc., Minneapolis, MN, USA).

A total of 20 runs designed according to the three-variable and five-level CCD were consisted of 8 combinations of factorial points, 6 combinations of axial points, and 6 replicates of center point. The variation of response value versus the 3 dominant variables $\left(X_{1}, X_{2}\right.$, and $\left.X_{3}\right)$ was fitted into following response surface quadratic model:

$$
Y=\sum \beta_{\mathrm{i}} X_{\mathrm{i}}+\sum \beta_{\mathrm{ii}} \mathrm{X}_{\mathrm{i}}^{2}+\sum \beta_{\mathrm{ij}} \mathrm{X}_{\mathrm{i}} \mathrm{X}_{\mathrm{j}}+\beta_{0}
$$

where $\mathrm{Y}$ was the response value (FRAP, TEAC, and TPC value); $X_{i}$ and $X_{j}$ were the independent variables; $\beta_{\mathrm{i}}, \beta_{\mathrm{ii}}, \beta_{\mathrm{ij}}$, and $\beta_{0}$ were the coefficients of the linear, quadratic, interactive, and constant terms, respectively.

ANOVA was carried out to test the adequacy of the fitted model at a significant level of $p<0.05$. The 3D surface plots were utilized to visualize the individual and interactive effects of independent variables on the response value. Besides, the verified experiment was conducted to verify the accuracy of the fitted model. 


\subsection{Animal Study}

The supernatant obtained under optimal MAE procedure was evaporated to dryness by vacuum rotary evaporator. Then, the dried crude extract was dissolved in distilled water at concentrations of 10, 20, and $40 \mathrm{~g} / \mathrm{L}$.

The 30 male Kunming mice weighing 18-22 g were purchased from Experimental Animal Center of Sun Yat-sen University, and housed in SPF animal room (12 h light/dark cycle, $22 \pm 0.5{ }^{\circ} \mathrm{C}$, $40-60 \%$ relative humidity). All procedures were strictly executed according to the principles of "laboratory animal care and use" approved by Sun Yat-sen University (No. 2017-011; 21 November 2017). Mice were randomly divided into 5 groups (6 mice each), namely control group, model group, and 3 treatment groups.

The 3 treatment groups were fed intragastrically with $0.2 \mathrm{~mL} / 10 \mathrm{~g}$ body weight of herbal tea at different doses $(200,400$, and $800 \mathrm{mg} / \mathrm{kg}$, according to the literature [23]) for 7 days, while the control and model groups were treated with corresponding distilled water. The model and 3 treatment groups were administrated with $52 \%(v / v)$ alcohol $(10 \mathrm{~mL} / \mathrm{kg}$ body weight, i.g.) $30 \mathrm{~min}$ after the last administration, while the control group was ingested with corresponding distilled water. All animals were weighed and anesthetized $6 \mathrm{~h}$ later.

The blood samples were collected after removing eyeball, then centrifuged at $3600 \mathrm{~g}$ for $10 \mathrm{~min}$ twice. The levels of AST, ALT, ALP, TBIL, and TG of the separated serums were measured by chemistry analyzer (AU5821; Beckman Coulter K.K., Tokyo, Japan). The liver was harvested and weighed. One piece of the liver was immersed in $4 \%(w / v)$ paraformaldehyde, embedded in paraffin, and sliced for staining with hematoxylin-eosin (H\&E). The $0.200 \mathrm{~g}$ liver tissue was homogenized in $1.8 \mathrm{~mL}$ ice-cold $0.9 \% \mathrm{NaCl}$ solution. The homogenate $(10 \%, w / v)$ was centrifuged at $2500 \mathrm{~g}$ for $10 \mathrm{~min}$ to obtain supernatant, which was used for determining the levels of TP, TG, MDA, GSH, SOD, and CAT according to kits instructions. The significant increase of MDA content, and decreases of GSH, SOD, and CAT activities in the model group indicate the occurrence of alcohol-induced oxidative damage in liver [22].

\subsection{HPLC Assay}

The phenolic profile of the herbal tea, which was acquired using the optimal parameters, were identified and quantified according to the method reported by Cai et al. with little modifications [35]. HPLC system was equipped with photodiode array detector (PAD) (Waters, Milford, MA, USA) and Agilent Zorbax Extend-C18 column $(5 \mu \mathrm{m}, 4.6 \mathrm{~mm} \times 250 \mathrm{~mm})$. The HPLC procedure was set as follows: mobile phase A of $0.1 \%$ formic acid in water; mobile phase B of methanol; temperature of $40{ }^{\circ} \mathrm{C}$; flow rate of $0.8 \mathrm{~mL} / \mathrm{min}$; elution gradient of $95 \% \mathrm{~A}$ (0 min), 80\% A (15 min), 70\% A (20 min), $63 \%$ A (25 min), 60\% A (40 min), 50\% A (60 min), 50\% A (65 min), 95\% A (65.1 min), 95\% A (70 min). The retention time, UV-vis spectrum, and peak area (under the maximal absorption wavelength) were compared with those of standards to identify and quantify phenolic compounds in the herbal tea, and the content was expressed as $\mathrm{mg} / \mathrm{g}$ DW.

\subsection{Data Analysis}

All tests were conducted in triplicate, and the values were expressed as mean $\pm \mathrm{SD}$ (standard deviation). Data analysis was performed using SPSS 20.0. For comparison between more than two groups, one-way ANOVA was used, and followed by a LSD post hoc test, with a significant level of 0.05. For correlations between values of FRAP, TEAC, and TPC, Pearson test was utilized.

\section{Conclusions}

The optimized extraction parameters $\left(53.04 \mathrm{~mL} / \mathrm{g}\right.$ of S/M ratio, $65.52{ }^{\circ} \mathrm{C}, 30.89 \mathrm{~min}$, and $\left.500 \mathrm{~W}\right)$ guaranteed the maximal yield of antioxidants from Five-Golden-Flowers tea. The in vitro antioxidant assays indicated that the herbal tea possessed considerable ABTS radical scavenging activities, 
$\mathrm{Fe}^{3+}$ reducing power, as well as high content of phenolic compounds. The in vivo animal experiment illustrated that the herbal tea exerted antioxidant properties against alcohol-induced oxidative damage in liver via enhancing antioxidant enzyme activity and reducing lipid peroxidation. Moreover, the phenolic compounds, the major antioxidant contributors of the herbal tea, were detected using HPLC, with rutin, chlorogenic acid, epicatechin, gallic acid, and $p$-coumaric acid being identified and quantified. All of the results supported the role of Five-Golden-Flowers tea as a potential source of natural antioxidants, which could be utilized as functional foods for the prevention of oxidative stress-induced diseases.

Author Contributions: Conceptualization, H.-B.L. and C.-N.Z.; Methodology, C.-N.Z. and G.-Y.T.; Software, X.-Y.X.; Validation, C.-N.Z. and G.-Y.T.; Formal Analysis, Q.L.; Investigation, C.-N.Z., G.-Y.T., Q.L., X.-Y.X. S.-Y.C., K.-Y.Z. and S.-L.M.; Data Curation, C.-N.Z.; Writing-Original Draft Preparation, C.-N.Z.; Writing-Review \& Editing, R.-Y.G. and H.-B.L.; Supervision, H.-B.L.; Project Administration, H.-B.L.; Funding Acquisition, H.-B.L.

Funding: This research was funded by the National Natural Science Foundation of China (No. 81372976), Key Project of Guangdong Provincial Science and Technology Program (No. 2014B020205002), and the Hundred-Talents Scheme of Sun Yat-sen University.

Conflicts of Interest: The authors declare no conflict of interest.

\section{References}

1. Zhang, Y.J.; Gan, R.Y.; Li, S.; Zhou, Y.; Li, A.N.; Xu, D.P.; Li, H.B. Antioxidant phytochemicals for the prevention and treatment of chronic diseases. Molecules 2015, 20, 21138-21156. [CrossRef] [PubMed]

2. Zhao, C.N.; Meng, X.; Li, Y.; Li, S.; Liu, Q.; Tang, G.Y.; Li, H.B. Fruits for prevention and treatment of cardiovascular diseases. Nutrients 2017, 9, 598. [CrossRef] [PubMed]

3. Fu, L.; Xu, B.T.; Gan, R.Y.; Zhang, Y.; Xu, X.R.; Xia, E.Q.; Li, H.B. Total phenolic contents and antioxidant capacities of herbal and tea infusions. Int. J. Mol. Sci. 2011, 12, 2112-2124. [CrossRef] [PubMed]

4. Li, A.N.; Li, S.; Li, H.B.; Xu, D.P.; Xu, X.R.; Chen, F. Total phenolic contents and antioxidant capacities of 51 edible and wild flowers. J. Funct. Food. 2014, 6, 319-330. [CrossRef]

5. Jin, L.; Li, X.; Tian, D.; Fang, X.; Yu, Y.; Zhu, H.; Ge, Y.; Ma, G.; Wang, W.; Xiao, W.; et al. Antioxidant properties and color parameters of herbal teas in China. Ind. Crop. Prod. 2016, 87, 198-209. [CrossRef]

6. Fu, Y.; Yang, J.; Cunningham, A.B.; Towns, A.M.; Zhang, Y.; Yang, H.; Li, J.; Yang, X. A billion cups: The diversity, traditional uses, safety issues and potential of Chinese herbal teas. J. Ethnopharmacol. 2018, 222, 217-228. [CrossRef] [PubMed]

7. Fu, L.; Xu, B.T.; Xu, X.R.; Gan, R.Y.; Zhang, Y.; Xia, E.Q.; Li, H.B. Antioxidant capacities and total phenolic contents of 62 fruits. Food Chem. 2011, 129, 345-350. [CrossRef]

8. Wong, S.; Leong, L.; Williamkoh, J. Antioxidant activities of aqueous extracts of selected plants. Food Chem. 2006, 99, 775-783. [CrossRef]

9. Oroian, M.; Escriche, I. Antioxidants: Characterization, natural sources, extraction and analysis. Food Res. Int. 2015, 74, 10-36. [CrossRef] [PubMed]

10. Routray, W.; Orsat, V. Microwave-assisted extraction of flavonoids: A review. Food Bioprocess Technol. 2012, 5, 409-424. [CrossRef]

11. Altemimi, A.; Choudhary, R.; Watson, D.G.; Lightfoot, D.A. Effects of ultrasonic treatments on the polyphenol and antioxidant content of spinach extracts. Ultrason. Sonochem. 2015, 24, 247-255. [CrossRef] [PubMed]

12. Zhang, J.J.; Li, Y.; Lin, S.J.; Li, H.B. Green extraction of natural antioxidants from the Sterculia nobilis fruit waste and analysis of phenolic profile. Molecules 2018, 23, 1059. [CrossRef] [PubMed]

13. Chen, Y.; Xie, M.; Gong, X. Microwave-assisted extraction used for the isolation of total triterpenoid saponins from Ganoderma atrum. J. Food Eng. 2007, 81, 162-170. [CrossRef]

14. Kala, H.K.; Mehta, R.; Sen, K.K.; Tandey, R.; Mandal, V. Critical analysis of research trends and issues in microwave assisted extraction of phenolics: Have we really done enough. TrAC-Trends Anal. Chem. 2016, 85, 140-152. [CrossRef]

15. Florez, N.; Conde, E.; Dominguez, H. Microwave assisted water extraction of plant compounds. J. Chem. Technol. Biotechnol. 2015, 90, 590-607. [CrossRef]

16. Bouras, M.; Chadni, M.; Barba, F.J.; Grimi, N.; Bals, O.; Vorobiev, E. Optimization of microwave-assisted extraction of polyphenols from Quercus bark. Ind. Crop. Prod. 2015, 77, 590-601. [CrossRef] 
17. Dahmoune, F.; Nayak, B.; Moussi, K.; Remini, H.; Madani, K. Optimization of microwave-assisted extraction of polyphenols from Myrtus communis L. leaves. Food Chem. 2015, 166, 585-595. [CrossRef] [PubMed]

18. Bhuyan, D.J.; Quan, V.V.; Chalmers, A.C.; van Altena, I.A.; Bowyer, M.C.; Scarlett, C.J. Microwave-assisted extraction of Eucalyptus robusta leaf for the optimal yield of total phenolic compounds. Ind. Crop. Prod. 2015, 69, 290-299. [CrossRef]

19. Li, Y.; Li, S.; Lin, S.J.; Zhang, J.J.; Zhao, C.N.; Li, H.B. Microwave-assisted extraction of natural antioxidants from the exotic Gordonia axillaris fruit: Optimization and identification of phenolic compounds. Molecules 2017, 22, 1481. [CrossRef] [PubMed]

20. Altemimi, A.; Lightfoot, D.A.; Kinsel, M.; Watson, D.G. Employing response surface methodology for the optimization of ultrasound assisted extraction of lutein and $\beta$-Carotene from Spinach. Molecules 2015, 20, 6611-6625. [CrossRef] [PubMed]

21. Yu, F.; Li, H.; Meng, Y.; Yang, D. Extraction optimization of Angelica sinensis polysaccharides and its antioxidant activity in vivo. Carbohydr. Polym. 2013, 94, 114-119. [CrossRef] [PubMed]

22. Zhang, Y.J.; Zhou, T.; Wang, F.; Zhou, Y.; Li, Y.; Zhang, J.J.; Zheng, J.; Xu, D.P.; Li, H.B. The effects of Syzygium samarangense, Passiflora edulis and Solanum muricatum on alcohol-induced liver injury. Int. J. Mol. Sci. 2016, 17, 1616. [CrossRef] [PubMed]

23. Wu, S.; Zhang, N.; Shen, X.; Mei, W.; He, Y.; Ge, W. Preparation of total flavonoids from loquat flower and its protective effect on acute alcohol-induced liver injury in mice. J. Food Drug Anal. 2015, 23, 136-143. [CrossRef] [PubMed]

24. Zhou, T.; Zhang, Y.J.; Xu, D.P.; Wang, F.; Zhou, Y.; Zheng, J.; Li, Y.; Zhang, J.J.; Li, H.B. Protective effects of lemon juice on alcohol-induced liver injury in mice. Biomed. Res. Int. 2017, 2017, 7463571. [CrossRef] [PubMed]

25. Granato, D.; Shahidi, F.; Wrolstad, R.; Kilmartin, P.; Melton, L.D.; Hidalgo, F.J.; Miyashita, K.; Camp, J.V.; Alasalvar, C.; Ismail, A.B.; et al. Antioxidant activity, total phenolics and flavonoids contents: Should we ban in vitro screening methods? Food Chem. 2018, 264, 471-475. [CrossRef] [PubMed]

26. Cederbaum, A.I.; Lu, Y.; Wu, D. Role of oxidative stress in alcohol-induced liver injury. Arch. Toxicol. 2009, 83, 519-548. [CrossRef] [PubMed]

27. Massey, V.L.; Arteel, G.E. Acute alcohol-induced liver injury. Front. Physiol. 2012. [CrossRef] [PubMed]

28. Meng, X.; Li, Y.; Li, S.; Gan, R.Y.; Li, H.B. Natural products for prevention and treatment of chemical-induced liver injuries. Compr. Rev. Food. Sci. Food Saf. 2018, 17, 472-495. [CrossRef]

29. Li, W.; Qu, X.N.; Han, Y.; Zheng, S.W.; Wang, J.; Wang, Y.P. Ameliorative effects of 5-hydroxymethyl-2-furfural (5-HMF) from Schisandra chinensis on alcoholic liver oxidative injury in mice. Int. J. Mol. Sci. 2015, 16, 2446-2457. [CrossRef] [PubMed]

30. Huo, X.W.; Liu, C.Q.; Gao, L.; Xu, X.D.; Zhu, N.L.; Cao, L. Hepatoprotective effect of aqueous extract from the seeds of Orychophragmus violaceus against liver injury in mice and HepG2 cells. Int. J. Mol. Sci. 2017, 18, 1197. [CrossRef] [PubMed]

31. Yang, J.; Guo, J.; Yuan, J. In vitro antioxidant properties of rutin. LWT-Food Sci. Technol. 2008, 41, 1060-1066. [CrossRef]

32. Gao, Z.H.; Xu, H.B.; Huang, K.X. Effects of rutin supplementation on antioxidant status and iron, copper, and zinc contents in mouse liver and brain. Biol. Trace Elem. Res. 2002, 88, 271-279. [PubMed]

33. Kim, H.; Pan, J.H.; Kim, S.H.; Lee, J.H.; Park, J. Chlorogenic acid ameliorates alcohol-induced liver injuries through scavenging reactive oxygen species. Biochimie 2018, 150, 131-138. [CrossRef] [PubMed]

34. Li, A.N.; Li, S.; Zhang, Y.J.; Xu, X.R.; Chen, Y.M.; Li, H.B. Resources and biological activities of natural polyphenols. Nutrients 2014, 6, 6020-6047. [CrossRef] [PubMed]

35. Cai, Y.; Luo, Q.; Sun, M.; Corke, H. Antioxidant activity and phenolic compounds of 112 traditional Chinese medicinal plants associated with anticancer. Life Sci. 2004, 74, 2157-2184. [CrossRef] [PubMed]

Sample Availability: Samples of Five-Golden-Flowers tea and several phenolic standards are available from the authors. 